\title{
PET-MRI tracking of imaging-visible microencapsulated stem cells in immunocompetent rabbits
}

\author{
Yingli Fu ${ }^{1 *}$, Ronnie Mease ${ }^{1}$, Ying Chen ${ }^{1}$, Guan Wang ${ }^{1,2}$, Dorota Kedziorek', Meiyappan Solaiyappan', \\ Dara Kraitchman ${ }^{1}$
}

From 16th Annual SCMR Scientific Sessions

San Francisco, CA, USA. 31 January - 3 February 2013

\section{Background}

Exogenous stem cell therapy has shown benefits for treating peripheral arterial disease patients, who are not amenable for conventional revascularization therapy. Previously, we have demonstrated the ability of imaging-visible cell microencapsulation to overcome the challenges of poor cell retention/survival and difficulties with monitoring cell delivery success. However, in vivo cell viability cannot be assessed noninvasively. Here, we investigate the potential of PET-MRI tracking of ${ }^{19} \mathrm{~F}$ MRI-visible microencapsulated human mesenchymal stem cells (hMSCs) labeled with triple-fusion (TF) reporter gene in non-immunosuppressed rabbits.

\section{Methods}

Bone marrow-derived hMSCs were stably transfected with a lentiviral vector encoding firefly luciferase, red fluorescence protein, and thymidine kinase. Alginate cell microencapsulation was performed using a modification to incorporate perfluorooctylbromide (PFOB). Bioluminescence imaging (BLI, Xenogen IVIS 2000) was acquired before and after cell encapsulation to assess in vitro cell viability. Rabbits received either intramuscular injection of PFOB-encapsulated TF-hMSCs in the medial thigh followed by intravenous administration of [18F] 9-[4-fluoro-3-(hydroxymethy) butyl] guanine ([18F]FHBG) $(\mathrm{n}=7,1.7 \pm 0.7 \mathrm{mCi})$, or PFOB-encapsulated TFhMSCs that were pre-incubated with [18F]-FHBG $(\mathrm{n}=3$, $55 \pm 2 \mu \mathrm{Ci}$ ). Dynamic PET imaging (Siemens HRRT CPS Innovation) was acquired immediately or $60 \mathrm{~min}$ after

${ }^{1}$ Radiology and Radiological Science, Johns Hopkins University, Baltimore, MD, USA

Full list of author information is available at the end of the article transplantation for 30-90 min. Proton (3D GRE, TR/ $\mathrm{TE}=15 / 5.45 \mathrm{~ms}, \mathrm{FOV}=186 \times 230 \mathrm{~mm}$, voxel size $=0.45 \mathrm{x}$ $0.45 \times 1.5 \mathrm{~mm}$ ) and 19F MRIs (TrueFISP, Siemens Tim Trio, TR/TE $=4.1 / 2.0 \mathrm{~ms}, 32$ averages, $\mathrm{FOV}=250 \times 250 \mathrm{~mm}$, image matrix $=192 \times 192, \mathrm{BW}=1002 \mathrm{~Hz} /$ pixel, voxel size $=$ $1.3 \times 1.3 \times 1.25 \mathrm{~mm}$ ) were obtained 1-2 days after delivery. PET images were fused with $1 \mathrm{H} / 19 \mathrm{~F}$ MR to identify the location of transplanted cells. Follow-up PET imaging was repeated within 1-14 days with intravenous or ultrasoundguided intramuscular $(0.7 \pm 0.3 \mathrm{mCi} /$ thigh $)$ of administration of [18F]-FHBG. Follow-up 19F MRIs were acquired 1-2 days after PET imaging. BLI was performed 2 weeks after delivery.

\section{Results}

In vitro hMSC viability and transgene expression were not affected by encapsulation or [18F]-FHBG incubation as determined by BLI and live/dead cell staining $(91 \pm 6 \%)$. All PFOB cap injections were identified on ${ }^{19} \mathrm{~F}$ MRI in vivo (Figure 1A). Using PET, PFOB microcapsule injection site in rabbit thigh was identified as "hot spot" (Figure 1B) and showed high concordance to the MRI "hot spot" (Figure 1C). No significant volume change of PFOB Caps was observed on ${ }^{19} \mathrm{~F}$ MRI over 2 weeks. BLI demonstrated viable xenogeneic TF-hMSCs in PFOB microcapsules 2 week post delivery (Figure 1D).

\section{Conclusions}

We demonstrate xenogeneic MSC delivery in non-immunosuppressed large animals using novel MRI-visible microencapsulation and reporter gene labeling. PFOB microencapsulation of TF-hMSCs enables cell tracking and viability assessment using clinical PET-MRI. 


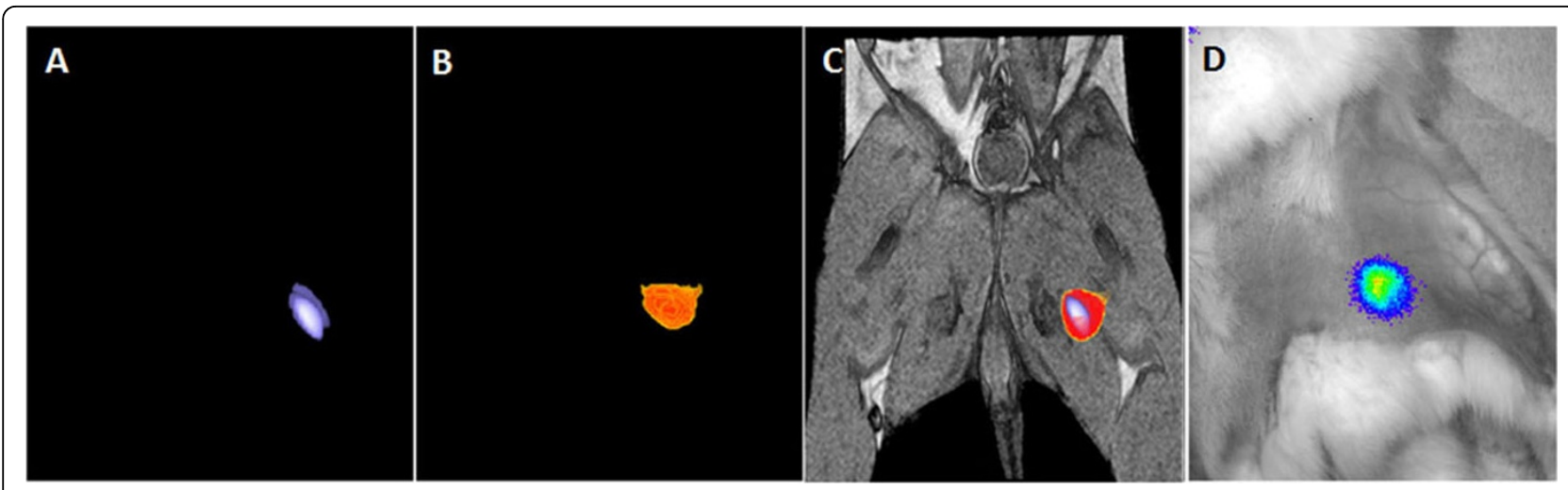

Figure $1(\mathrm{~A}){ }^{19} \mathrm{~F}$ MR image of PFOB Caps containing TF-hMSCs in a the rabbit thigh; (B) PET image of PFOB Caps in the same rabbit; (C) Fusion of ${ }^{19} \mathrm{~F}$ MR image (blue) and PET image (red) with anatomical "H MR showing the concordance "hot spot" and the location of PFOB Caps injection site; (D) Bioluminescence imaging of the rabbit revealing highly viable encapsulated TF-hMSCs 2 weeks after delivery.

\section{Funding}

Funding support was provided by NIH R21/R33-HL89029 \& MD-SCRFII-039.

\section{Author details}

${ }^{1}$ Radiology and Radiological Science, Johns Hopkins University, Baltimore, MD, USA. ${ }^{2}$ Electrical and Computer Engineering, Johns Hopkins University, Baltimore, MD, USA.

Published: 30 January 2013

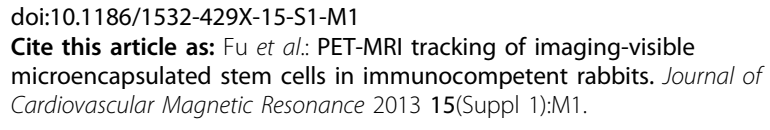

\section{Submit your next manuscript to BioMed Central} and take full advantage of:

- Convenient online submission

- Thorough peer review

- No space constraints or color figure charges

- Immediate publication on acceptance

- Inclusion in PubMed, CAS, Scopus and Google Scholar

- Research which is freely available for redistribution 